\title{
Analysis of air flow velocity distribution in the intake system of an SI engine
}

The conditions of air flow in the intake determine power generated by the engine to a large extent. The biggest resistances in flow of the air sucked or pumped into the engine are generated by the throttle, which is at the same time the main component which allows for regulation of engine power. For the purpose of research conducted in this work, time density of engine work points in analyzed velocity profiles was determined with the use of Engine Road Load Simulator. Thanks to the knowledge of time velocity, it was possible to determine throttle positions at which the engine operates most frequently. With the use of image analysis methods, obtained parameters were experimentally researched, considering flow disturbances which are the effect of air flow through the throttle and uneven air distribution in the intake manifold of a four-cylinder engine.

Key words: intake manifold, PIV, flow, throttle, filling ratio

\section{Introduction}

The air flow process in the IC engine intake system affects the cylinder filling ratio, therefore affecting its performance. Power is one the main operation indicators of modern engines, and efforts to increase it are constantly undertaken. The main ways of obtaining more engine power are: getting more fresh air to the cylinders by increasing the air pressure in the manifold, lowering air temperature and minimizing flow resistances in the intake manifold. In a multi-cylinder engine it is also important to evenly distribute the air between cylinders. In IC engines where the fuel dosing system is situated at the beginning of the intake system (i.e. carburetors or Single Point Injection), uneven air supply results in uneven engine operation. In newer designs, equipped with Multi Point Injection systems, fuel is delivered separately to each cylinder, however its distribution is based on the measured air flow for all cylinders. In such cases, the uneven air distribution results not only in uneven engine operation, but also in increased harmful substance emissions, including carbon dioxide. The application of newest technologies, such as broadband lambda sensors (two per one cylinder in 4-2-1 exhaust systems) partially solves this problem. However, this design can naturally be implemented after the combustion process already took place. Moreover, in most cases a single, narrow-band lambda sensor is used. The main source of information about the quality of a combustion process is the quantity of free oxygen contained in exhaust gasses. The fuel dosage is adjusted so that a stoichiometric fuel-air ratio $(\lambda=$ $1)$ is maintained. This means that the air-fuel ratio computed by the ECU is a mean value for all cylinders. Despite proper mean value of air-fuel ratio, a situation where lean burning occurs for some cylinders and rich burning occurs for the other ones.

Maintaining a stoichiometric air-fuel ratio for all cylinders on an IC engine is a challenge for many automotive research and science centers. One of the main solutions to this problem is an intake manifold designed with the following factors in mind:

1. Ensuring an even filling ratio for all cylinders,

2. Measure the mass of air delivered to each cylinder separately,
3. In the future- to use separate pressure sensors for each cylinder, which will allow to implement corrections in fuel dosage, taking into account both to engine operating parameters and engine wear.

In this work the authors on researching the phenomenon of air distribution in the intake manifold of an IC engine were focused.

\section{Scope of research}

The experimental research conducted on a real-life object are time consuming and costly. A way to reduce research costs and time is to implement simulation techniques. In the Chair of Road and Agricultural Vehicles at Opole University of Technology, a Road Engine Load Simulator was conceived. It utilizes a virtual engine, saved in a numerical form in computer memory, which allows for realization of simulation of drive cycles. Such simulations allow to facilitate recognition of key operating points in the scope of engine operating characteristics.

The main indicator of IC engine operation used by car manufacturers is the engine power, which in many cases exceeds $70 \mathrm{~kW}$. However, power utilization in real-life driving conditions is significantly lower, rarely reaching the maximum value of engine power- which only occurs during very intense accelerations and near maximum vehicle speed.

Observation of simulation results shown on graphs in Fig. 2 it can be seen that mean power utilization for city driving cycles does not exceed $30 \mathrm{~kW}$, being only slightly larger for out-of-city driving cycles, namely under $50 \mathrm{~kW}$.

Management of engine power is realized mostly by means of lowering or increasing the cylinder filling ratio, which is possible due to changes in throttle position angle. Especially in SI engines, low filling ratio values are obtained for fully closed or only partially opened throttle. For researched driving cycles, it is possible to determine throttle operation points at different engine speeds which result from drivetrain operating conditions. Most densely occupied areas in Fig. 1 show most frequent engine operation fields during simulated driving cycles. 

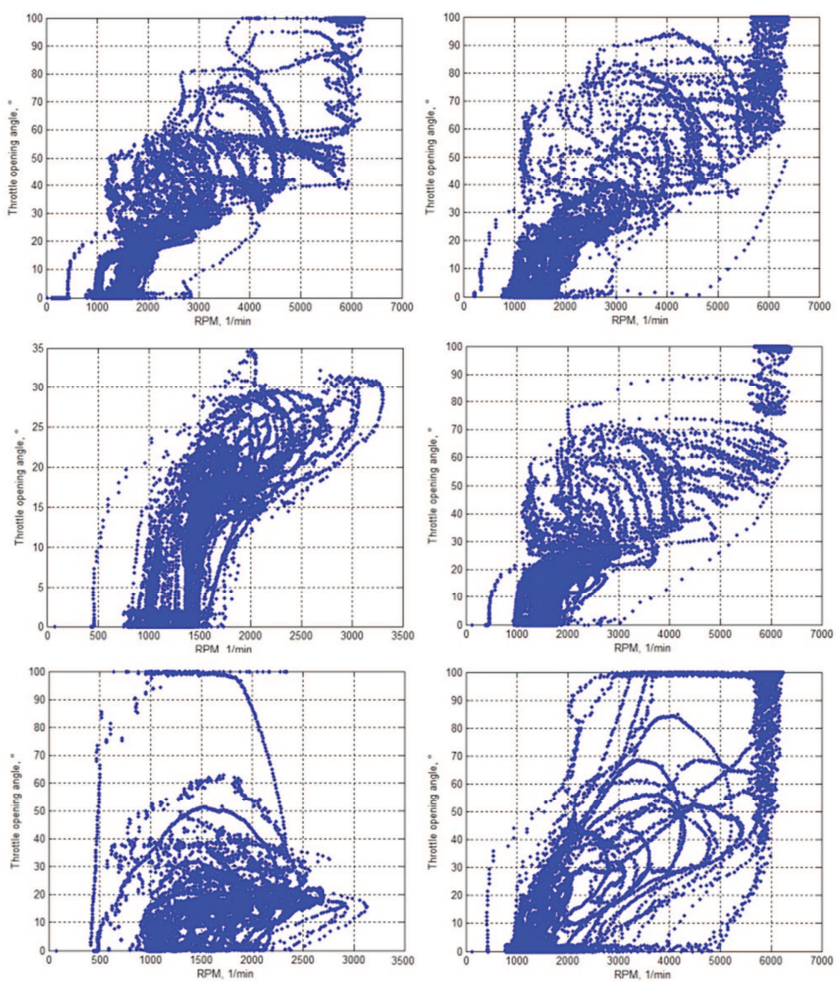

Fig. 1. Engine operation point density during realization of chosen driving cycles

The analysis of graphs presented in fig. 1 shows that the greatest density of engine operation points occurs at $10^{\circ}, 20^{\circ}$ and $30^{\circ}$ throttle position and engine speeds of 1500 and 2000 RPM.

Each throttle position value for specific engine speed has a corresponding specific values of cylinder filling ratio, which is shown in Fig. 3.
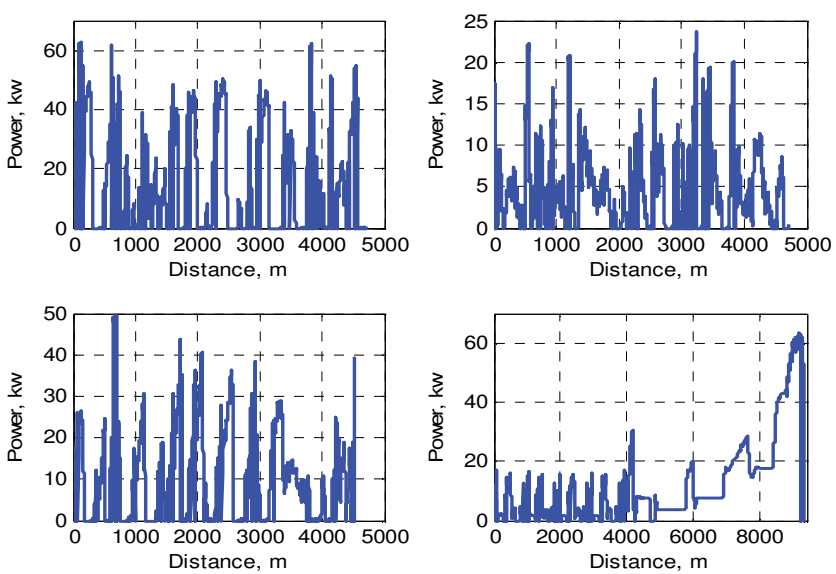

Fig. 2. Utilization of engine power during realization of chosen drive cycles

Despite the relations not being linear, it is clearly noticeable that with the increase in throttle position angle, filling ratio also increases. Biggest differences can be noted for throttle position angles between 0 and 45 degrees, while they are not so significant between 45 and 90 degrees.

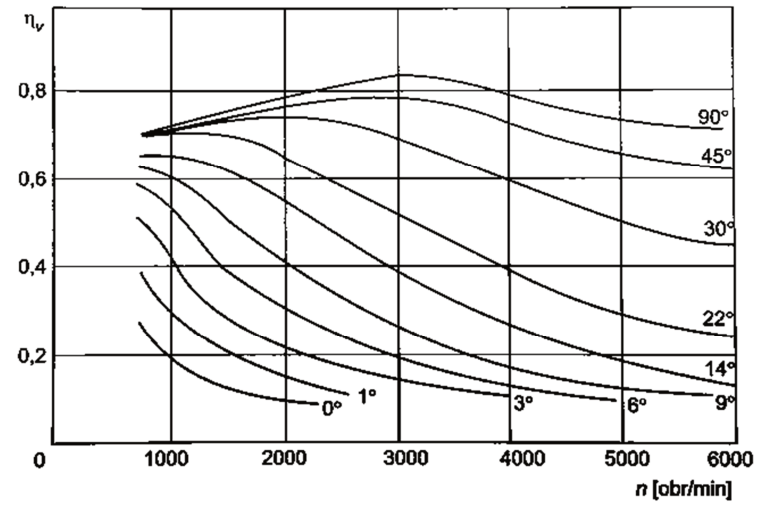

Fig. 3. Characteristics of cylinder filling ratio in relation to throttle inclination and engine speed [8]

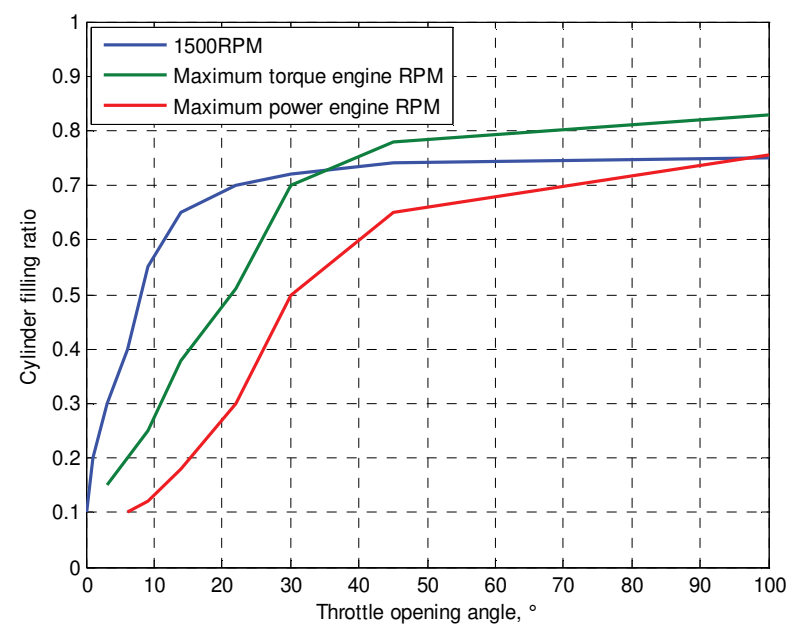

Fig. 4. Characteristics of cylinder filling ratio in relation to engine speed for chosen throttle repeal angles

By reading data from Figs 3 and 4, it can be inferred that the lower throttle position values have the biggest role in engine power management- this is especially evident in Fig. 4. At higher throttle position angles, the effect is not so prominent. This confirms the earlier observation, that engine operation points occurring at $10^{\circ}, 20^{\circ}$ i $30^{\circ}$ throttle position and engine speeds of 1500 and 2000 RPM should be subject to further analysis.

For chosen parameters the amount of air flowing through the intake system was computed, taking into account the corresponding cylinder filling ratios.

$$
\mathrm{V}=\mathrm{V}_{\mathrm{s}} \cdot \mathrm{n} \cdot 60 \cdot 2
$$

where: $\mathrm{V}$ - volume of air, $\mathrm{V}_{\mathrm{s}}$ - engine capacity, $\mathrm{n}$ - engine speed.

Table 1. Volume of air flowing through the intake at chosen operating points

\begin{tabular}{|c|c|c|}
\hline & 1500 RPM & 2000 RPM \\
\hline $10^{\circ}$ & $37 \mathrm{~m}^{3} / \mathrm{h}$ & $40 \mathrm{~m}^{3} / \mathrm{h}$ \\
\hline $20^{\circ}$ & $49 \mathrm{~m}^{3} / \mathrm{h}$ & $60 \mathrm{~m}^{3} / \mathrm{h}$ \\
\hline $30^{\circ}$ & $52 \mathrm{~m}^{3} / \mathrm{h}$ & $71 \mathrm{~m}^{3} / \mathrm{h}$ \\
\hline
\end{tabular}

\section{Digital Particle Image Velocimetry}

The literature study on the subject of an intake manifolds shows that most of the research is based on computer 
simulations. The analysis of multiphase flow research methods has led the authors to conclude that it is possible to conduct experimental research of engine intake manifold through the use of DPIV (Digital Particle Image Velocimetry) method. The DPIV method relies on registering flow phenomena with the use of laser light sheet technique, for visualization of velocities vector fields, as shown in fig. 5 . Lasers of different kinds (both constant and impulseoperating) are used as light sources. The use of laser light sheet technique allows to obtain a camera view area within a single chosen plane. In most cases of DPIV application, for calculation of the velocity vector field is also necessary to introduce additional inert seeding particles into circulation.

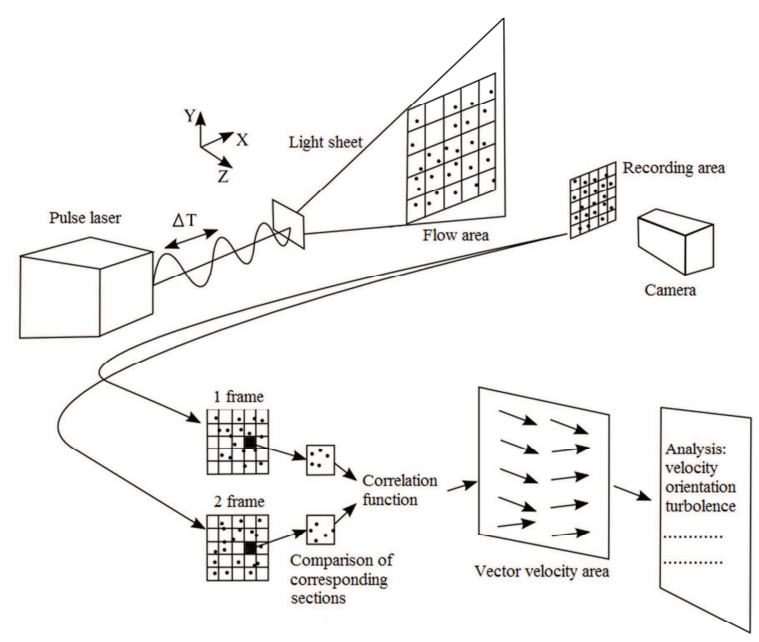

Fig. 5. Measurement scheme of DPIV method [11]

A video camera registers a series of images of flow area illuminated by the laser at a specified frequency and recorded images in double frame technology. In this technology every single image consists of two frames of image, separated by a time interval $\Delta \mathrm{T}$ called the Time Between Pulse (TBP). Obtained images are being analysed in the aspect of changes the concentration of seeding particles suspended in the flowing gas. The result is that the seeding particle distribution from the first image is recognize in the second one, as shown in fig. 6. To find a mean seeding particles translation value, a Cross Correlation Function (CCF) method is used. Those computations are done according to Wiener-Kinchin law, which states that autocorrelation and power spectral density are equal to each other and linked by Fourier transform, given by equation below $[5]$.

$$
F(i, k)=\beta_{O} \sum_{m=0}^{M-1} \sum_{n=0}^{N-1} O(m, n) \exp \left(\frac{-j 2 \pi m i}{M}\right) \exp \left(\frac{-j 2 \pi n k}{N}\right)
$$

for $\mathrm{m}=0,1, \ldots, \mathrm{M}-1 ; \mathrm{n}=0,1, \ldots, \mathrm{N}-1$

where:

$$
\mathrm{O}(\mathrm{m}, \mathrm{n})=\beta_{\mathrm{F}} \sum_{\mathrm{i}=0}^{\mathrm{M}-1} \sum_{\mathrm{k}=0}^{\mathrm{N}-1} \mathrm{~F}(\mathrm{i}, \mathrm{k})_{\mathrm{O}} \exp \left(\frac{\mathrm{j} 2 \pi \mathrm{mi}}{\mathrm{M}}\right) \exp \left(\frac{\mathrm{j} 2 \pi \mathrm{nk}}{\mathrm{N}}\right)
$$

for $\mathrm{i}=0,1, \ldots, \mathrm{M}-1 ; \mathrm{k}=0,1, \ldots, \mathrm{N}-1$

$$
\beta_{\mathrm{O}} \cdot \beta_{\mathrm{F}}=\frac{1}{\mathrm{M} \cdot \mathrm{N}}
$$

The researched plane is divided into squares of known dimensions for the purpose of analysis. It is recommended to use sections of $32 \times 32$ pixels, assuming the translation of researched particles is no bigger than $33 \%$ of the analyzed square [9]. It is considered a good practice to run an initial research with the aim of estimating image capture time before beginning the main course of research. The assumption of excessively long image capture time would result in the seeding particle moving too far to be noticed by the computation algorithm, whereas a too short timespan would mean that the seeding particle would not change its position in the researched square. A correct choice of image capture time to be as short as possible while allowing the seeding particle to move, drastically increases measurement accuracy.
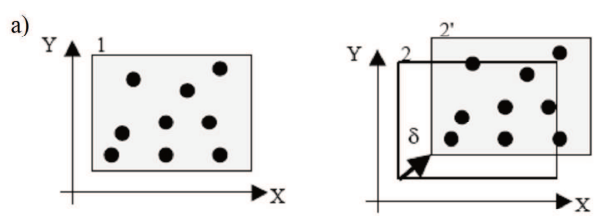

b)
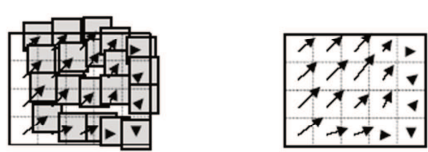

Fig. 6. (Division of captured images into sections - research ares and designation of movement vectors for each section. 1-image section 1, 2image section 2, 2 'image sections 1 found in section $2 \delta$-translation of section 2 ' in relations to section 1 , conversion of translations to velocity vector field) [10]

Before captured images can be subject to verification by the DPIV algorithms mentioned above, it is recommended to carry out a series of image processing with the use of graphics software. In a situation where the area of interest does not fully fill the camera view area it is recommended to apply an image mask, which will exclude unwanted areas from the recorded image. Next, every pair of recorded images is subject to geometrical analysis, which searched for areas of pixel concentration that are constant in position (creation of background image). The generated background image is subtracted from all raw images of the recording session. The effect of this subtraction is a new series of images which show only moving seeding particles in interest area. Measurements which are prepared in such a way lower the risk of occurrence of hiss caused by uneven lighting etc. Generation of image depicting the flow of seeding particles which is free of interruptions requires capturing a series of images, conducting full calculations for each image, and then averaging of obtained results.

\section{Experimental setup for research of phenomena in the intake manifold}

To understand the real-life phenomena occurring in the intake, a series of experiments was conducted, utilizing a modified intake manifold from a Volkswagen 9A engine. The manifold was modified in a way that retains its original 
geometry while allowing for the use of DPIV method. Front wall along with two side walls was removed to allow the use of the laser light sheet technique for flow visualization with the use of a camera. To ensure airtightness of the system, the missing walls were replaced with components made of transparent plastic. Flow direction consistent with real engine operating conditions was forced with the use of Helios MVZ315 fan, which sucked the air out of the manifold. The quantity of the air flowing through the system was regulated with the use of fan speed regulator and engine throttle mounted in its original position on the manifold. To preserve flow conditions similar to an on-engine situation, a stock intake pipe was installed before the throttle. Laser light sheet with the use of Nano L 200-15 PIV 1200mJ Laser produced by Litron Lasers was generated. A Dantec Dynamics FlowSense EO 4M camera perpendicularly to the laser light sheet was placed. Engine operating parameters and corresponding with them flow parameters chosen in previous chapters of this research, required specific TBP. Applied TBP value for each measuring series on volume of air and throttle position angle were depended. In the research the following values of TBP were finally adopted: for throttle position angle equal to 10 degrees and both values of volume of air assumed TBP equal to $60 \mu \mathrm{s}$, for others throttle position angle TBP only on the volume of air were depended and were respectively $40 \mu \mathrm{s}$ (for 49 and 52 $\mathrm{m}^{3} / \mathrm{h}$ ) and $60 \mu \mathrm{s}$ (for 60 and $71 \mathrm{~m}^{3} / \mathrm{h}$ ). Each double frame image in the measurement series with $10 \mathrm{~Hz}$ frequency were captured.

A Flow Visualization Components R700CE Flow Tracker which generates seeding particles of $2 \div 5 \mu \mathrm{m}$ diameters was placed near the air inlet of the system. Aerosol of the Di-Ethyl-Hexyl-Sebacat (DEHS) was used as seeding particles for DPIV method.

Series of trials with the aim of determining a needed amount of seeding particles were carried out. The purpose was to determine an optimum outflow pressure from the Lasskin nozzle in the flow tracker to ensure a proper concentration of seeding particles in captured images of flow.

For better mixing of seeding particles with the drawn in air, a two-meter long circular pipe was installed before the intake manifold. A Siemens VDO 5WK97002 Mass Air Flow sensor was installed at the half of intake length to ensure a proper amount of the air flowing through the sys-

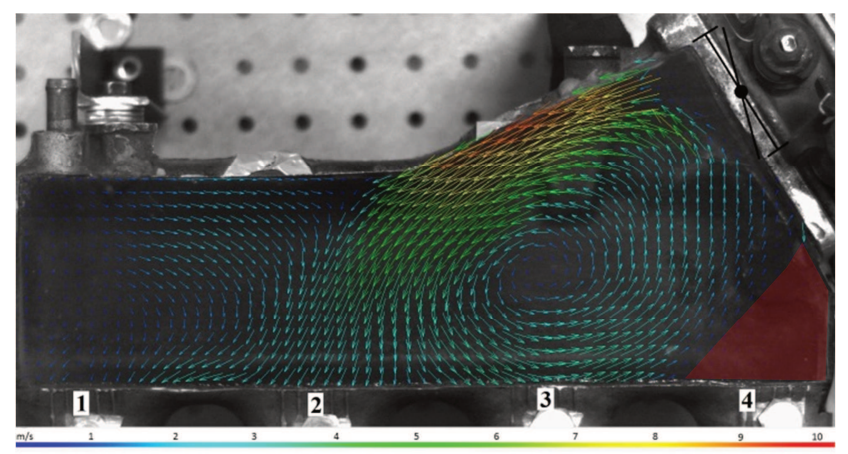

Fig. 8. Velocity vector distribution and air flow direction in the intake manifold at 1500 RPM engine speed and $10^{\circ}$ throttle position angle tem. In the research all image analysis were carry out with the use of Dantec Dynamics Dynamic Studio 4.1 software.

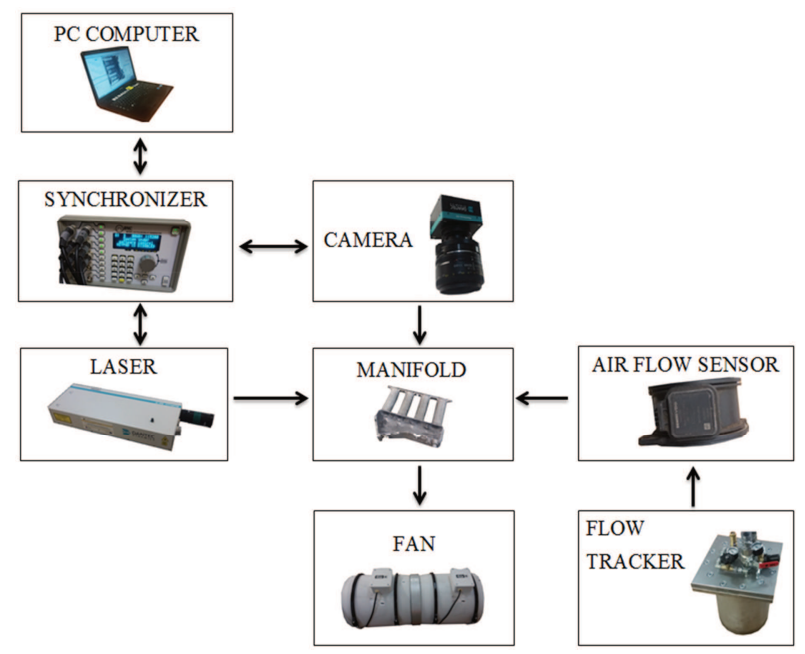

Fig. 7. Scheme of experimental setup

\section{Research results}

According to the DPIV method described in the chapter 3 , it is assumed that the seeding particles move identically to the flowing air through the manifold. Therefore Velocity vector field generated by the computational algorithm illustrate real air flow through the investigated intake manifold (Fig. 8). Consequently colored vectors depict velocity and movement direction of air flow in manifold. The research describes the flow of medium in a plane corresponding to the center of intake canals distributing air to the cylinder head. It is common to use this localization for DPIV imaging $[2,4]$. Some elements of the intake manifold made of original material (aluminum) reflected the laser light sheet, which significantly interfered with the research. In the effect reflecting green laser beam caused noise in those areas. This resulted in measurements being disturbed in the areas where the air flow is slower. Usual in such cases attenuation by shifting the histogram of the brightness of the image would become a barrier that would prevent recognition of the seeding particles at the present lower limit of brightness. For this reason, during the analysis an

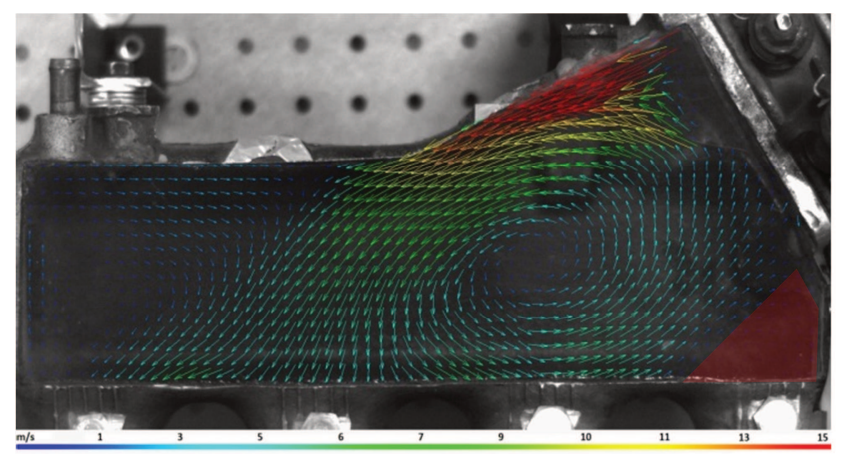

Fig. 9. Velocity vector distribution and air flow direction in the intake manifold at $2000 \mathrm{RPM}$ engine speed and $10^{\circ}$ throttle position angle 


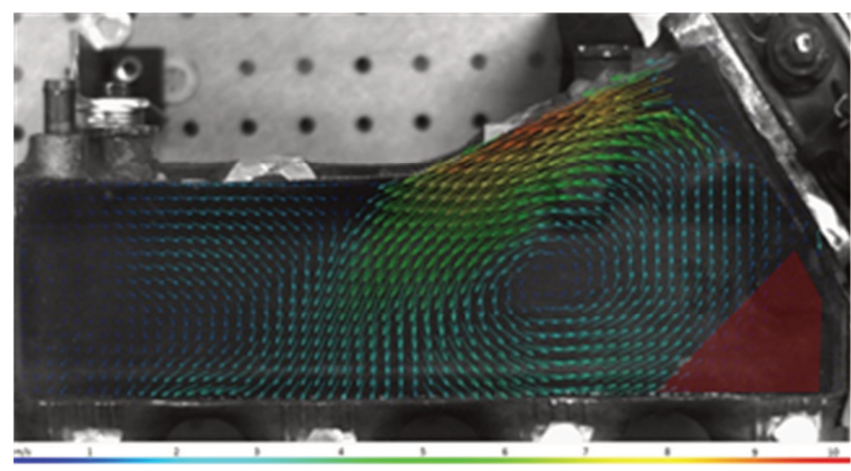

Fig. 10. Velocity vector distribution and air flow direction in the intake manifold at $1500 \mathrm{RPM}$ engine speed and $20^{\circ}$ throttle position angle

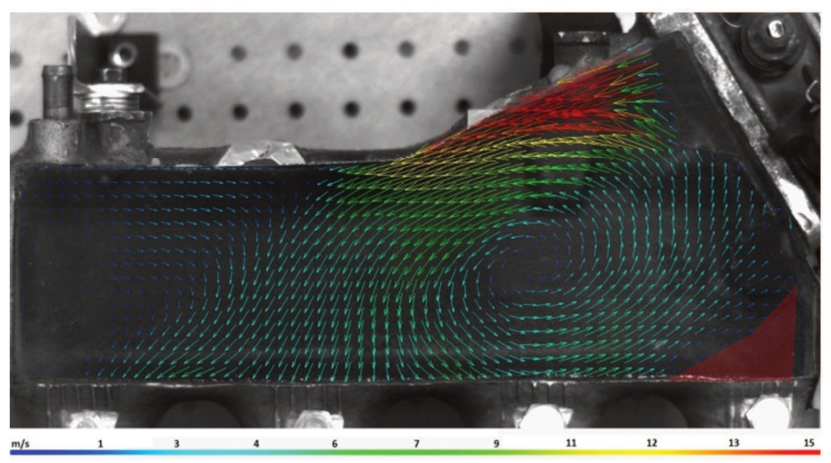

Fig. 11. Velocity vector distribution and air flow direction in the intake manifold at $2000 \mathrm{RPM}$ engine speed and $20^{\circ}$ throttle position angle

additional image mask was used. Image masking process had to be erased flawed areas in the DPIV computations algorithm. The procedure was also done in Dynamic Studio 4.1 software. The areas with errors resulting from such state of things were marked red in Figs 8-13. Markings used in the later parts of this work are shown in Fig. 8, which also naturally refer to Figs 9-13. By observing vector fields depicted in Figs 8-13, it can be clearly seen that for all of research parameters, significant whirl occur in the air collecting part of the intake manifold. It can be inferred that this adversely affects the air filling ratios of cylinders 1 and 4. For each researched case, biggest flow velocities occurred near the upper wall of the manifold, directly behind the throttle. It is assumed that this unevenness in flow

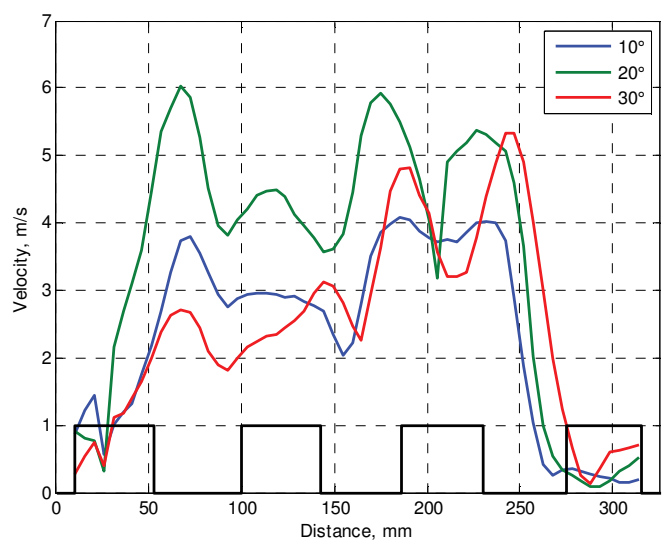

Fig. 14. Air velocity profiles in the manifold outflow plane for different throttle position angles at $1500 \mathrm{RPM}$

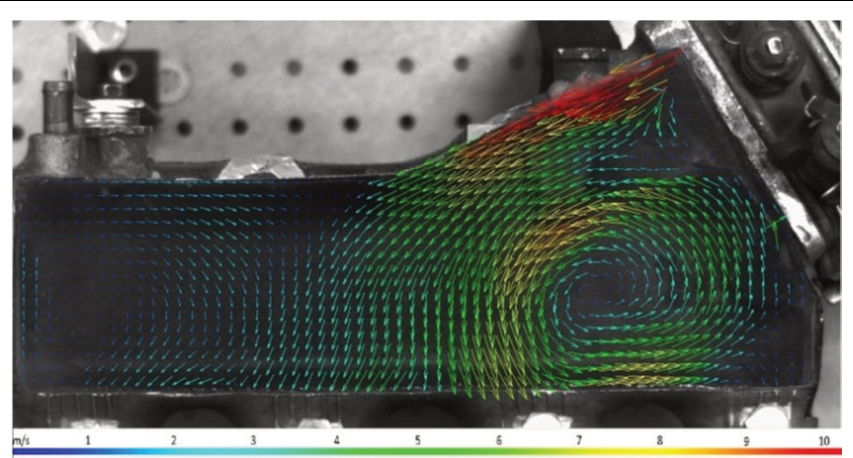

Fig. 12. Velocity vector distribution and air flow direction in the intake manifold at 1500 RPM engine speed and $30^{\circ}$ throttle position angle

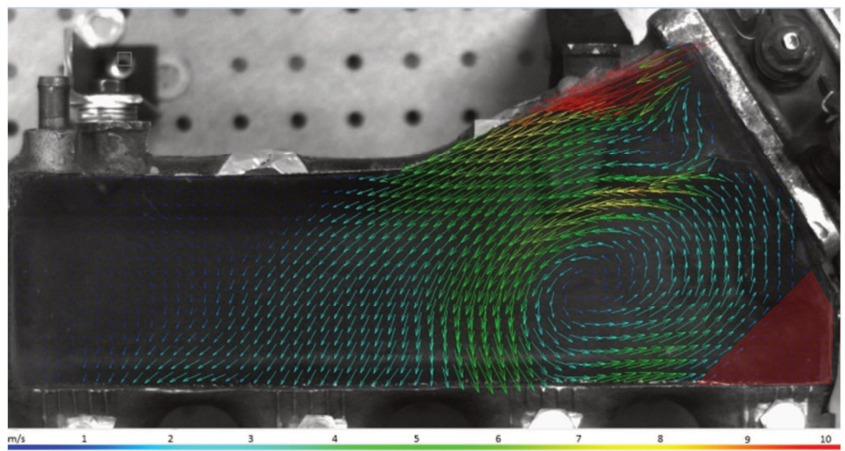

Fig. 13. Velocity vector distribution and air flow direction in the intake manifold at $2000 \mathrm{RPM}$ engine speed and $30^{\circ}$ throttle position angle

between the sides of the throttle can be the effect of the air eddying in the original intake pipe placed before the throttle mechanism. The ejecting effect of the air particles moving with high velocity causes suction of the air flowing through the other side of the throttle plate and affects the formation of whirl visible above the inlets to cylinders 3 and 4. A clearly visible flow at both sides of the throttle is present only for throttle position angles of over 30 degrees.

It can be noticed that at these parameters the whirl diameter is significantly lower, as are flow velocity differences above inlets to cylinders 3 and 4.

It was seen that for each of the analyzed cases, the whirl formation also occurs in a part of the manifold situated at the opposing end of the throttle mechanism.

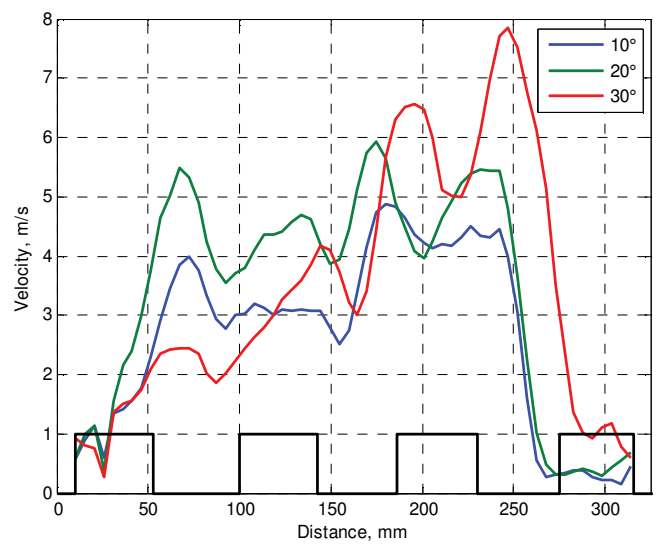

Fig. 15. Air velocity profiles in the manifold outflow plane for different throttle position angles at 2000 RPM 
This results in air movement along the manifold walls in a direction opposite to the air stream entering the inlet. Therefore it can be concluded that redesigning the original intake pipe section (mounted before the throttle) and the section situated at the opposing end of the throttle mechanism would result in an improvement in this situation.

Figs. 14 and 15 shows experimentally obtained air velocity profiles for select engine speeds and throttle positions occurring just above the row of inlet canals of the manifold.

Black outlines drawn at the lower part of graphs schematically depict manifold shape while retaining real scale in $\mathrm{X}$ axis. Lines situated at value of 1 at velocity axis show the location of air outlet, while the remaining space corresponds to places where baffles between inlets are situated.

Highest velocities at manifold outlet areas for 1500 RPM engine speed occur at throttle position angle of 20 degrees, and highest inflow speeds were noted for cylinder 3. However, it has to taken into account that this velocity is the resultant velocity of inflow and whirl velocities.

Flow velocities obtained for 2000 RPM are characterized by bigger variations in value between cylinders and retain similar tendencies for all throttle positions. It is interesting that velocities of air particles are higher near inlet canal baffles, where the air flows between them, than at the manifold outlets. It is possible that redesigning outlet shapes would result in an improvement in air outflow conditions.

\section{Summary}

Both simulation and experimental results have shown that point of maximum engine power and torque are not the most commonly utilized engine working parameters.
DPIV technique is very sensitive to any neglect and inaccuracies that can occur during the course of research. Meticulously preparing the experimental setup in a way to provide as even lighting as possible without causing unnecessary flashes, as well as the need to experimentally verify image capture parameters multiple times for each flow velocity has elongated and complicated the whole research process. However, conducted measurement have shown that it is possible to use the DPIV technique for examination and analysis of engine intake manifold. The obtained results have shown significant differences in air distribution between cylinders. Variations in fresh air supply between cylinders can result in different values of air excess factors, therefore causing elevated harmful substance emissions to the environment.

The conducted research depicts free air flow through the intake manifold. They do not however fully show the real conditions of forced air flow in IC engines. Air momentum forced by the fan does not cause pulsations, which occur in real-life conditions due to piston operation and pulsating nature of valvetrain operation.

It can be assumed that shown measurement results give an overall outlook on flow processes in the intake manifold, showing differences in the air flow occurring within it. Conducting the research presented in this work was essential to develop methodology for quantitative and qualitative analysis of air velocity distribution in the intake manifold with the use of DPIV technique.

[5] BENDAT, J.S., PIERSOL, A.G., Random data: analysis and measurement procedures. 4th Edition. Wiley, Hoboken, 2010.

[6] CUPIAŁ, K., DUŻYŃSKI, A., GRZELKA, J. Wpływ pulsacji ciśnienia w układzie dolotowym na rozdział świeżego ładunku w silniku gazowym. KONES 2000. Nałęczów 2000, 31-36.

[7] ŚWIĘCICKI, K. Konstrukcja układu dolotowego silnika spalinowego. Modelowanie Inżynierskie, 57, ISSN 1896$771 X$.

[8] ZAJĄC, P. Silniki pojazdów samochodowych. Podstawy budowy, diagnozowania i naprawy. WKŁ 2015.

[9] ADRIAN, R.J., WESTERWELL, J. Particle image velocimetry. Cambridge University Press, Cambridge 2011

[10] SUCHECKI, W., ALABRUDZIŃSKI, S. Metoda korekty wykresów pól prędkości w cyfrowej anemometrii obrazowej. Inżynieria i aparatura chemiczna. 2003, 42(34), 3, 14-20.

[11] www.dantecdynamics.com/measurement-principles-of-piv, $\mathrm{z}$ dnia 25.02.2017.

Jarosław Mamala, DSc., DEng. - Opole University of Technology.

e-mail: J.Mamala@po.opole.pl

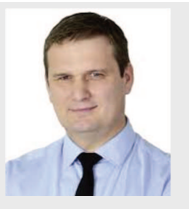

Andrzej Augustynowicz, DSc., DEng. - Opole University of Technology.

e-mail: A.Augustynowicz@po.opole.pl

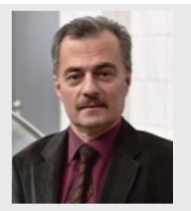

